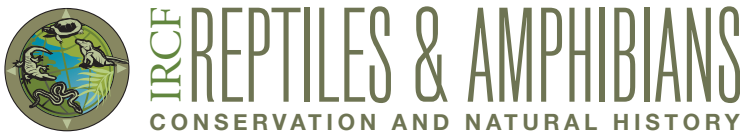

\section{Reproductive Biology of Female Northern African Rock Pythons (Python sebae) in Southern Florida, USA}

Robert W. Mendyk ${ }^{1,2}$, Kenneth L. Krysko ${ }^{3}$, Michael R. Rochford ${ }^{4}$, Sean-Patrick Wallace ${ }^{1}$, and Frank J. Mazzotti

'Department of Herpetology, Jacksonville Zoo and Gardens, Jacksonville, Florida 32218, USA (mendykr@jacksonvillezoo.org) ${ }^{2}$ Department of Herpetology, Smithsonian National Zoological Park, Washington, DC 20008, USA

${ }^{3}$ Division of Herpetology, Florida Museum of Natural History, Gainesville, Florida 32611, USA (kenneyk@ufl.edu)

${ }^{4}$ Fort Lauderdale Research and Education Center, University of Florida, Fort Lauderdale, Florida 33314, USA (miker@ufl.edu; fjma@ufl.edu)

$\mathrm{O}$ ver the past century, the state of Florida has seen the introduction and establishment of an unprecedented number of exotic amphibian and reptilian species, particularly in southern parts of the state. As of 2010, 56 nonnative herpetofaunal taxa, most of which are lizards, have become established (Krysko et al. 2011). Among Florida’s five established exotic snake species (Krysko et al. 2011), two species in the genus Python are established in southern Florida: the Burmese Python, P. bivittatus Kuhl 1820 (Meshaka et al. 2000) and the Northern African Rock Python, P. sebae (Gmelin 1789) (Reed et al. 2010; Fig. 1). Unlike P. bivittatus, which has been the focus of extensive environmental impact assessments (e.g.,

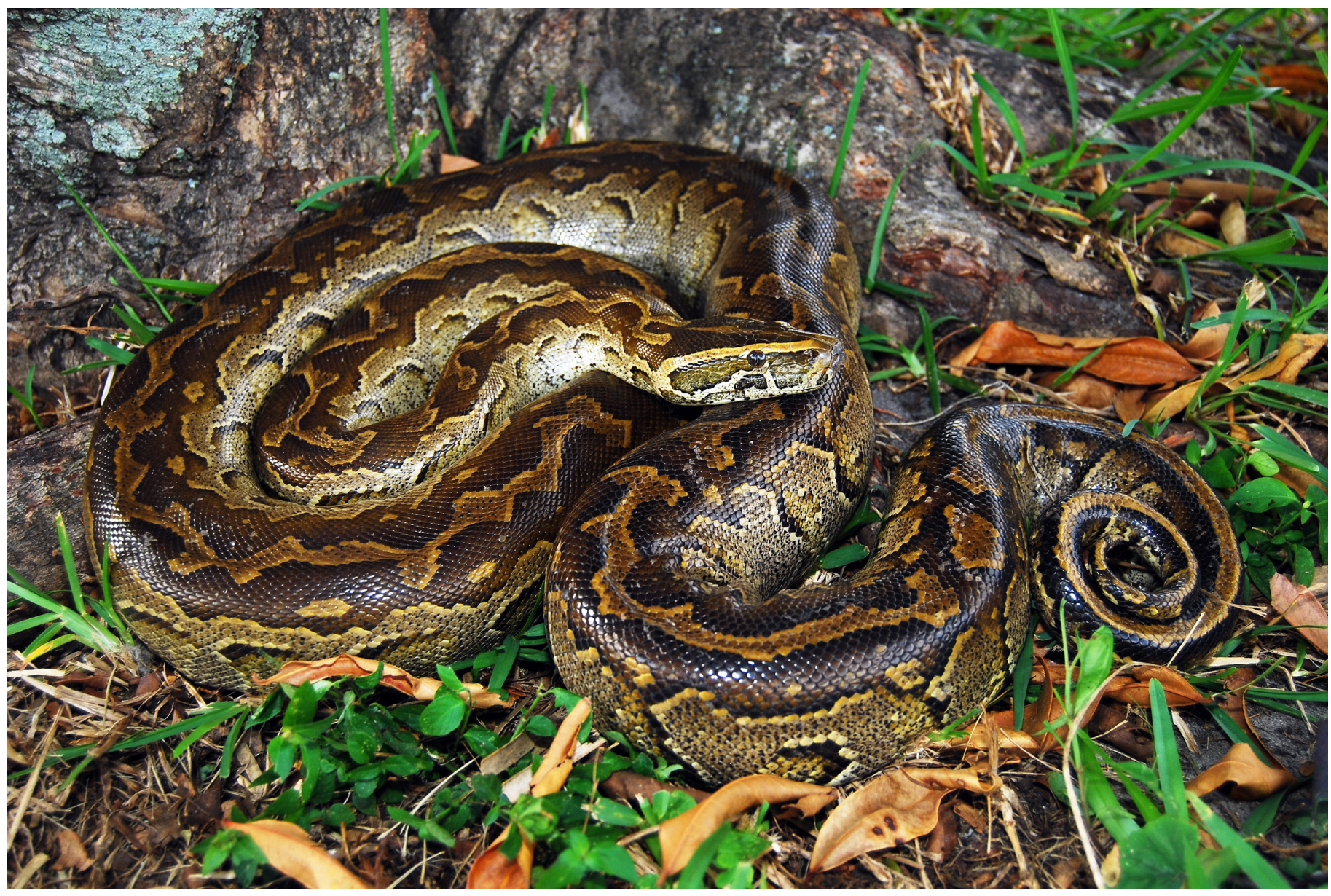

Fig. 1. An adult Northern African Rock Python (Python sebae) in Miami-Dade County, Florida (UF-Herpetology 169392). Photograph by Michael R. Rochford. 
Dorcas et al. 2012; Dove et al. 2011; Reed 2005) and studies on its ecology (e.g., Dorcas and Wilson 2011; Hart et al. 2012; Krysko et al. 2008, 2012; Mazzotti et al. 2011; Snow et al. 2007a,b; Snow et al. 2010), colonizing distributional limits (Barker and Barker 2008, 2009; Pyron et al. 2008; Rodda et al. 2009), and eradication (Mauldin and Savarie 2010; Reed et al. 2011a; Savarie et al. 2011), analogous studies are lacking for the Florida population of $P$. sebae.

Evidence of an introduced population of Python sebae in an approximately $10-\mathrm{km}^{2}$ area along the western border of Miami, Miami-Dade County, Florida, adjacent to Everglades National Park, was first documented in 2002 (Reed and Rodda 2009; Reed et al. 2010, 2011b). Since then, additional observations and captured individuals have been recorded from this area, including juveniles and adults of both sexes. Given the paucity of information available on the current ecological status of $P$. sebae in southern Florida, biological data derived from opportunistically field-collected snakes can yield important details on the natural history of the species as well as biotic and abiotic factors that may have facilitated its establishment. In this paper, we present reproductive data from wild-collected female P. sebae in Miami.

\section{Methods}

We compiled and examined data from 39 Python sebae collected from Miami, Miami-Dade County, Florida, curated in the Division of Herpetology, Florida Museum of Natural History, University of Florida (UF-Herpetology). Adults among the vouchered specimens were measured and dissected for dietary and reproductive data. Of these, we analyzed reproductive data from seven gravid $P$. sebae (Table 1) collected opportunistically between 2009 and 2013. One of these females (UF-Herpetology 169910) was collected in 2013 and transferred live to the Jacksonville Zoo and Gardens (JZG) for exhibition, where it was measured, weighed, and housed individually in a quarantine enclosure at the zoo's animal health center. After 30 days of refusing food, it was radiographed, revealing well-developed, shelled eggs within the oviducts. Subsequently, a nest box with moist sphagnum moss was provided for oviposition.

Voucher localities were georeferenced and plotted using ArcGIS version 10.1. On maps, our priority layers (lowest to highest) include records for the distribution of specimens, overlaid by samples we used for reproductive data (Fig. 2). A Pearson Product Moment Correlation was calculated to determine the relationship between snout-vent length (SVL) and clutch size (number of eggs). All statistical tests were conducted using SigmaStat (ver. 3.2); for all tests, $\alpha=0.05$; and data are reported \pm standard error.

\section{Results}

Reproductive data are provided in Table 1. Gravid females were collected between the months of January and May. Snout-vent lengths for gravid females ranged from 206.4$380.0 \mathrm{~cm}(\bar{x}=280.1 \pm 20.3)$. Clutch size ranged from 11-47 $(\bar{x}=32.1 \pm 4.7)$, and was positively correlated with female SVL (Fig. 3; $\mathrm{r}=0.79, \mathrm{n}=7, \mathrm{P}=0.035$ ).

On 8 May 2013, the single live snake (UF-Herpetology 169910, JZG 413309) weighed $6.12 \mathrm{~kg}$ and began oviposition the following day. Over a 17-day span, 11 eggs were deposited. Although several of these eggs were white and turgid and initially had the appearance of being viable, incubation was unsuccessful and all eggs deteriorated by 29 May 2015. On 13 June, this female weighed $4.47 \mathrm{~kg}$, illustrating a $27.0 \%$ reduction in body mass since the day before oviposition began.

\section{Discussion}

Based on the presence of neonates to adults of both sexes including gravid females, we conclude that Python sebae is reproducing in southern Florida. The current population appears to occupy an area encompassing approximately 10 $\mathrm{km}^{2}$ (Reed and Rodda 2009; Reed et al. 2010).

Particularly noteworthy is the diminutive size (206.4 $\mathrm{cm} \mathrm{SVL;} 230 \mathrm{~cm}$ total length [TL]) of the female collected and transferred to the JZG. Branch (1988) noted that female $P$. sebae reach sexual maturity at $250 \mathrm{~cm}$ TL. Luiselli et al.

Table 1. Reproduction data for female Northern African Rock Pythons (Python sebae) in Miami-Dade County, Florida.

\begin{tabular}{cccccc}
$\begin{array}{c}\text { UF- } \\
\text { Herpetology }\end{array}$ & $\begin{array}{c}\text { Date of } \\
\text { Collection }\end{array}$ & $\begin{array}{c}\text { SVL } \\
(\mathbf{c m})\end{array}$ & $\begin{array}{c}\text { TL } \\
(\mathbf{c m})\end{array}$ & $\begin{array}{c}\text { Clutch } \\
\text { Size }\end{array}$ & Remarks \\
\hline 155725 & 30 May 2009 & 287 & 319 & 37 & \\
\hline 157215 & 12 Jan 2010 & 292 & 328.5 & 47 & \\
\hline 157303 & 16 Feb 2010 & 239 & 267.5 & 38 & \\
\hline 157328 & 26 Feb 2010 & 282 & 311 & 42 & \\
\hline 157785 & 20 Apr 2010 & 380 & 415 & 27 & JZG 413309 \\
\hline 169739 & 5 Mar 2013 & 274.4 & 302.2 & 11 & \\
\hline 169910 & 20 Mar 2013 & 206.4 & 230.4 & & \\
\hline
\end{tabular}




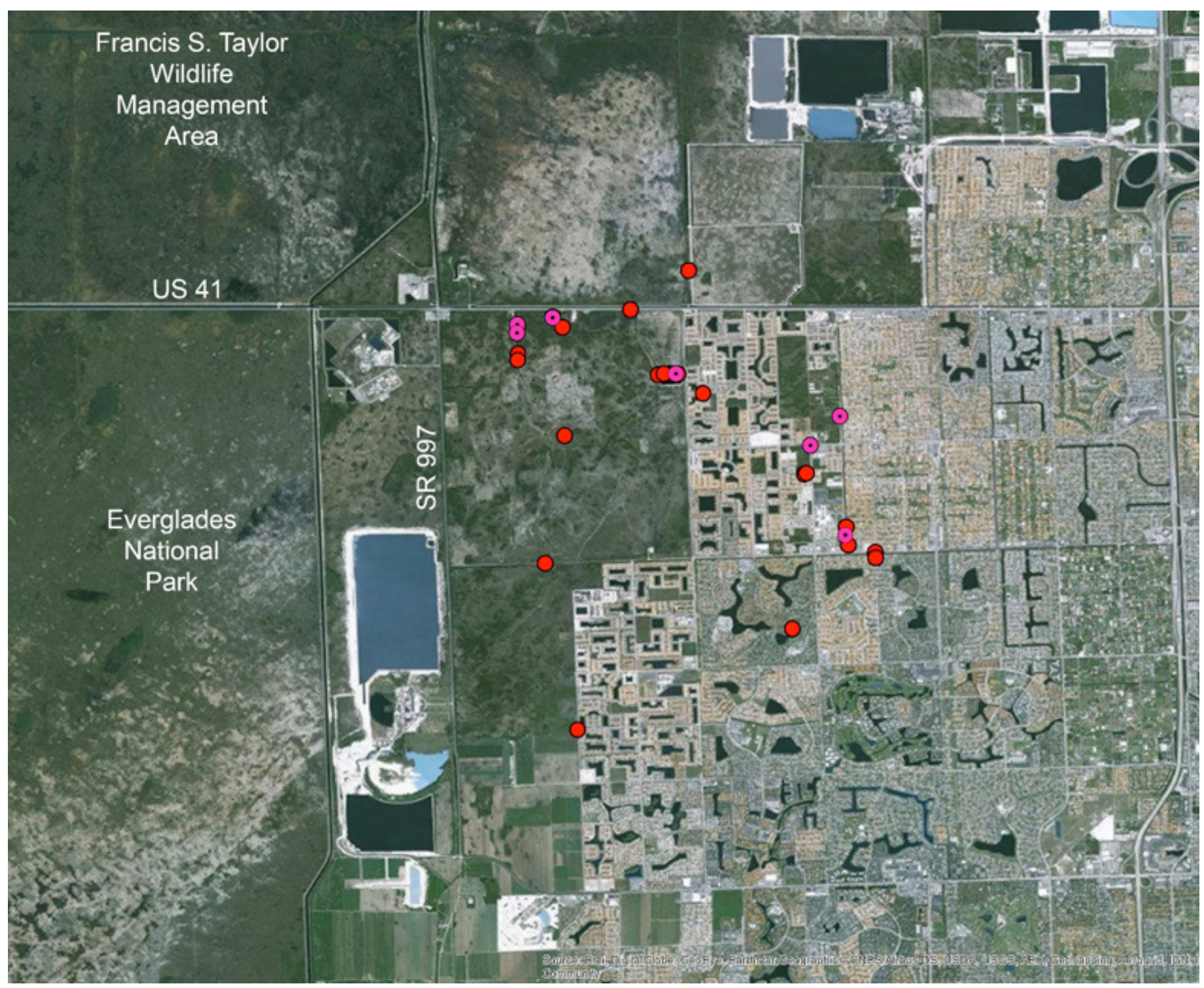

Fig. 2. Distribution of the Northern African Rock Python (Python sebae) in Miami-Dade County, Florida. Note that solid red circles represent confirmed localities $(n=40)$ and pink circles with black central dots represent localities of gravid females used in this study $(n=7)$ for reproductive data $($ Table 1$)$.

(2007) estimated that sexual maturation for both sexes of $P$. sebae is reached at $1.7 \mathrm{~m} \mathrm{SVL}(1.92 \mathrm{~m} \mathrm{TL})$, although it is not clear whether this was an approximation or a true measurement of live animals. Thus, the $230-\mathrm{cm}$ TL of the individual in this study may represent the smallest reproductive female documented for this species and suggests that females in southern Florida are capable of reproducing at small sizes.

Female P. sebae can produce up to 100 eggs per clutch (Barker and Barker 1994; Branch 1988; Marais 2004; Pope 1961; Spawls and Branch 1995) and clutch size is positively correlated with female body length (Reed and Rodda 2009; Stucki-Stirn 1979). In southern Florida, clutch sizes for the species were 11-47 eggs and were positively correlated with female body length. The 11-egg clutch produced by the smallest female in our study represents the smallest documented clutch size for the species.
The timing of egg production in our females may provide clues to the reproductive phenology of $P$. sebae in southern Florida (Fig. 4). Based on reproductive data derived from captivity, the duration between mating and oviposition in female P. sebae ranges between 30 and 70 days (Barker and Barker 1994; Lanza and Nistri 2005; Schmidt 1971). Since gravid females with oviductal eggs were collected between mid-January and May, this suggests that copulation occurred between December and April, during periods of decreased ambient air temperature, shortened photoperiod, and drier conditions. Oviposition could occur from February or March to May. Once laid, P. sebae eggs usually take 65-80 days to hatch (Barker and Barker 1994; Branch 1988; Lanza and Nistri 2005; Spawls and Branch 1995), depending on incubation temperature, which would place hatching between April and August. This projected timeframe is supported by documen- 


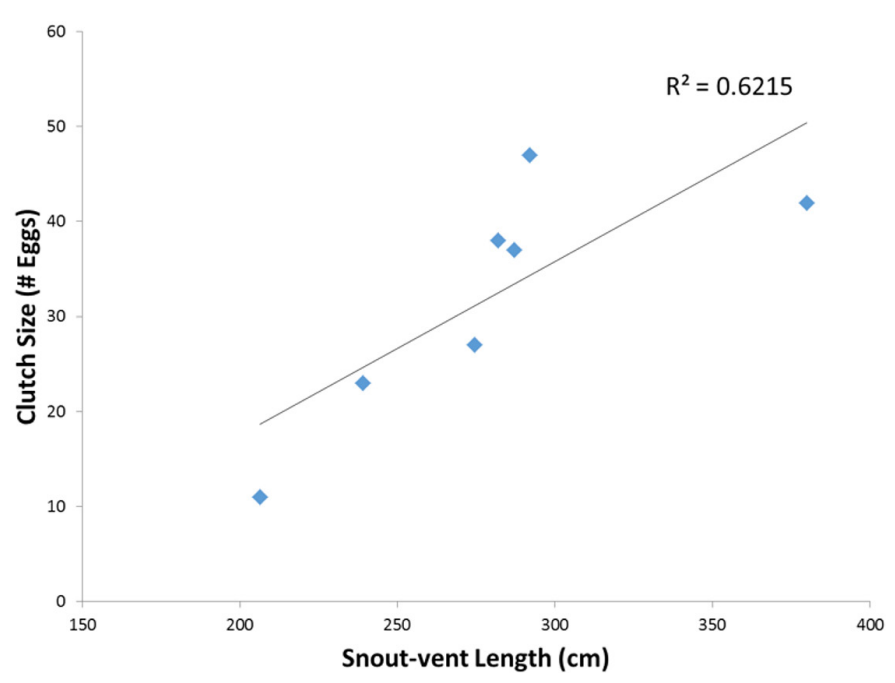

Fig. 3. Clutch size in relation to snout-vent length of Northern African Rock Pythons (Python sebae) in Miami-Dade County, Florida.

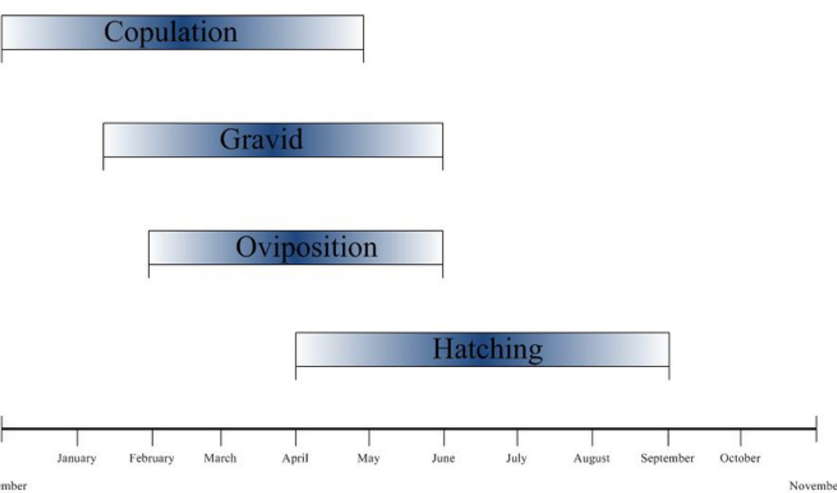

Fig. 4. Reproductive timeline for the Northern African Rock Python (Python sebae) in Miami-Dade County, Florida.

tation of a neonate collected from the same area in August 2009 (Reed et al. 2010).

We recommend python surveys that coincide with the time of year when females are most likely to be gravid to gain additional reproductive data that could be useful in understanding the species' biology, as well as serving as a way of reducing the population's size by removing reproductive females before they produce eggs and offspring. Moreover, if $P$. sebae forms breeding aggregations like its congener $P$. bivittatus in southern Florida (Smith et al. 2015), female P. sebae could potentially be used by researchers during the breeding season as a lure to attract, capture, and remove males from the population.

\section{Acknowledgments}

We thank various staff members of the Jacksonville Zoo and Gardens for collecting data and sharing useful information, photographs, and feedback; Jeffrey Fobb and the Florida Fish and Wildlife Conservation Commission for delivering the living snake to the zoo; Richard Green and the Smithsonian
Institution Libraries for procuring useful literature; and two anonymous reviewers for their constructive comments on an earlier draft of this manuscript.

\section{Literature Cited}

Barker, D. and T. Barker. 1994. The African giants. Vivarium 6: 18-21.

Barker, D.G. and T.M. Barker. 2008. The distribution of the Burmese Python, Python molurus bivittatus. Bulletin of the Chicago Herpetological Society 43: 33-38.

Barker, D.G. and T.M. Barker. 2009. A critique of the analysis used to predict the climate space of the Burmese Python in the United States by Rodda et al. 2008, 2009, and Reed and Rodda 2009. Bulletin of the Chicago Herpetological Society 45: 97-106.

Branch, B. 1988. Field Guide to the Snakes and Other Reptiles of Southern Africa. Ralph Curtis Books, Sanibel Island, Florida.

Dorcas, M.E. and J.D. Wilson. 2011. Invasive Pythons in the United States: Ecology of an Introduced Predator. University of Georgia Press, Athens.

Dorcas, M.E., J.D. Wilson, R.N. Reed, R.W. Snow, M.R. Rochford, M.A. Miller, W.E. Meshaka, P.T. Andreadis, F.J. Mazzotti, C.M. Romagosa, and K.M. Hart. 2012. Severe mammal declines coincide with proliferation of invasive Burmese Pythons in Everglades National Park. Proceedings of the National Academy of Sciences of the United States of America 109: 2418-2422.

Dove, C.J., R.W. Snow, M.R. Rochford, and F.J. Mazzotti. 2011. Birds consumed by the invasive Burmese Python (Python molurus bivittatus) in Everglades National Park, Florida, USA. Wilson Journal of Ornithology 123: 126-131.

Hart, K.M., P.J. Schoefield, and D.R. Gregorie. 2012. Experimentally derived salinity tolerance of hatchling Burmese Pythons (Python molurus bivittatus) from the Everglades, Florida (USA). Journal of Experimental Marine Biology and Ecology 413: 56-59.

Krysko, K.L., J.C. Nifong, R.W. Snow, and K.M. Enge. 2008. Reproduction of the Burmese Python (Python molurus bivittatus) in southern Florida. Applied Herpetology 5: 93-95.

Krysko, K.L., J.P. Burgess, M.R. Rochford, C.R. Gillette, D. Cueva, K.M. Enge, L.A. Somma, J.L. Stabile, D.C. Smith, J.A. Wasilewski, G.N. Kieckhefer III, M.C. Granatosky, and S.V. Nielsen. 2011. Verified non-indigenous amphibians and reptiles in Florida from 1863 through 2010: Outlining the invasion process and identifying invasion pathways and stages. Zootaxa 3028: 1-64.

Krysko, K.L., K.M. Hart, B.J. Smith, T.H. Selby, M.S. Cherkiss, N.T. Coutu, R.M. Reichart, L.P. Nunez, F.J. Mazzotti, and R.W. Snow. 2012. Record length, mass, and clutch size in the nonindigenous Burmese Python, Python bivittatus Kuhl 1820 (Squamata: Pythonidae), in Florida. Reptiles \& Amphibians 19: 267-270.

Lanza, B. and A. Nistri. 2005. Somali Boidae (genus Eryx Daudin 1803) and Pythonidae (genus Python Daudin 1803) (Reptilia Serpentes). Tropical Zoology 18: 67-136.

Luiselli, L., G.C. Akani, E.A. Eniang, and E. Politano. 2007. Comparative ecology and ecological modeling of sympatric pythons, Python regius and Python sebae, pp. 88-100. In: R.W. Henderson, and R. Powell (eds.), Biology of the Boas and Pythons. Eagle Mountain Publishing, Eagle Mountain, Utah.

Marais, J. 2004. A Guide to the Snakes of Southern Africa. Struik Publishers, Cape Town, South Africa.

Mauldin, R.E. and P.J. Savarie. 2010. Acetaminophen as an oral toxicant for Nile Monitor lizards (Varanus niloticus) and Burmese Pythons (Python molurus bivittatus). Wildlife Research 37: 215-222.

Mazzotti, F.J., M.S. Cherkiss, K.M. Hart, R.W. Snow, M.R. Rochford, M.E. Dorcas, and R.N. Reed. 2011. Cold-induced mortality of invasive Burmese Pythons in south Florida. Biological Invasions 13: 143-151.

Meshaka, W.E., Jr., W.F. Loftus, and T. Steiner. 2000. The herpetofauna of Everglades National Park. Florida Scientist 62: 84-103.

Pope, C.H. 1961. The Giant Snakes. Alfred A. Knopf, New York.

Pyron, R.A., F.T. Burbrink, and T.J. Guiher. 2008. Claims of potential expansion throughout the U.S. by invasive python species are contradicted by ecological niche models. PLoS ONE 3: e2931.

Reed, R.N. 2005. An ecological risk assessment of nonnative boas and pythons as potentially invasive species in the United States. Risk Analysis 25: 753-766.

Reed, R.N. and G.H. Rodda. 2009. Giant Constrictors: Biological and Management Profiles and an Established Risk Assessment for Nine Large Species of Pythons, Anacondas, and the Boa Constrictor. Open-file Report 2009-1202. U.S. Geological Survey, Reston, Virginia. 
Reed, R.N., K.L. Krysko, R.W. Snow, and G.H. Rodda. 2010. Is the Northern African Python (Python sebae) established in southern Florida? Reptiles \& Amphibians 17: 52-54.

Reed, R.N., K.M. Hart, G.H. Rodda, F.J. Mazzotti, R.W. Snow, M. Cherkiss, R. Rozar, and S. Goetz. 2011a. A field test of attractant traps for invasive Burmese Pythons (Python molurus bivittatus) in southern Florida. Wildlife Research 38: 114-121.

Reed, R.N., D. Giardina, T. Pernas, D. Hazelton, J.G. Dozier, J. Prieto, R.W. Snow, and K.L. Krysko. 2011b. Python sebae (Northern African Python or African Rock Python). Size. Herpetological Review 42: 303.

Rodda, G.H., C.S. Jarnevich, and R.N. Reed. 2009. What parts of the US mainland are climatically suitable for invasive alien pythons spreading from Everglades National Park? Biological Invasions 11: 241-252.

Savarie, P.J., R.M. Engeman, R.E. Mauldin, T. Mathies, and K.L. Tope. 2011. Tools for managing invasions: Acceptance of non-toxic baits by juvenile Nile Monitor lizards and Burmese Pythons under laboratory conditions. International Journal of Pest Management 57: 309-314.

Schmidt, C.H.M. 1971. Waarnemingen bij het broeden van Python sebae. Lacerta 29: 101, 105-106.

Smith, B.J., M.R. Rochford, M. Brien, M.S. Cherkiss, F.J. Mazzotti, S. Snow, and K.M. Hart. 2015. Largest breeding aggregation of Burmese Pythons (Python bivittatus) Kuhl 1820 (Squamata: Pythonidae) and implications for potential development of a control tool. Reptiles \& Amphibians 22: 16-19.

Snow, R.W., M.L. Brien, M.S. Cherkiss, L. Wilkins, and F.J. Mazzotti. 2007a. Dietary habits of the Burmese Python, Python molurus bivittatus, in Everglades National Park, Florida. Herpetological Bulletin 101: 5-7.

Snow, R.W., K.L. Krysko, K.M. Enge, L. Oberhofer, A. Warren-Bradley, and L. Wilkins. 2007b. Introduced populations of Boa constrictor (Boidae) and Python molurus bivittatus (Pythonidae) in southern Florida, pp. 416-438. In: R.W. Henderson and R. Powell (eds.), Biology of the Boas and Pythons. Eagle Mountain Publishing, Eagle Mountain, Utah.

Snow, R.W., A.J. Wolf, B.W. Greeves, M.S. Cherkiss, R. Hill, and F.J. Mazzotti. 2010. Thermoregulation by a brooding Burmese Python (Python molurus bivittatus) in Florida. Southeastern Naturalist 9: 403-405.

Spawls, S. and B. Branch. 1995. The Dangerous Snakes of Africa: Natural History, Species Directory, Venoms and Snakebite. Ralph Curtis Books, Sanibel Island, Florida.

Stucki-Stirn, M.C. 1979. A Comparative Study of the Herpetological Fauna of the Former West Cameroon/Africa, with a Classification and Synopsis of 95 Different Snakes and Descriptions of Some New Sub-species. Snake Report 721. HerpetoVerlag, Teuffenthal, Switzerland. 